\title{
Max Tech and Beyond: Fluorescent Lamps
}

\author{
Project Managers \\ Louis-Benoit Desroches \& Karina Garbesi \\ Environmental Energy Technologies Division
}

Author

Michael Scholand

N14 Energy Limited, Navigant Consulting Inc.

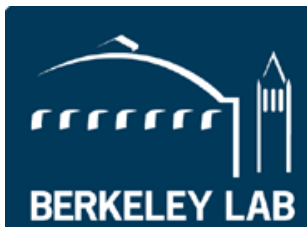

Lawrence Berkeley

National Laboratory

Lawrence Berkeley National Laboratory

One Cyclotron Road

Berkeley, CA 94720

April 1, 2012

The work described in this report was funded by the U.S. Department of Energy's Office of Energy Efficiency and Renewable Energy, Building Technologies Program under Contract No. DE-AC02-05CH11231. 


\section{Disclaimer}

This document was prepared as an account of work sponsored by the United States Government. While this document is believed to contain correct information, neither the United States Government nor any agency thereof, nor the Regents of the University of California, nor any of their employees, makes any warranty, express or implied, or assumes any legal responsibility for the accuracy, completeness, or usefulness of any information, apparatus, product, or process disclosed, or represents that its use would not infringe privately owned rights. Reference herein to any specific commercial product, process, or service by its trade name, trademark, manufacturer, or otherwise, does not necessarily constitute or imply its endorsement, recommendation, or favoring by the United States Government or any agency thereof, or the Regents of the University of California. The views and opinions of authors expressed herein do not necessarily state or reflect those of the United States Government or any agency thereof or the Regents of the University of California.

Lawrence Berkeley National Laboratory is an equal opportunity employer. 


\section{Acknowledgements}

The work described in this report was funded by the U.S. Department of Energy's Office of Energy Efficiency and Renewable Energy, Building Technologies Program under Contract No. DE-AC02-05CH11231. 


\section{Table of Contents}

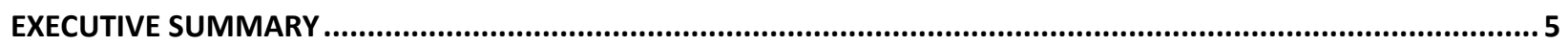

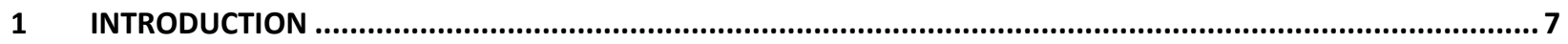

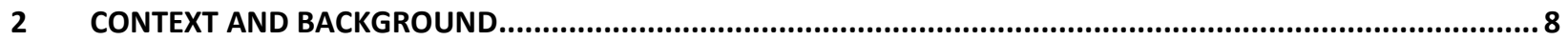

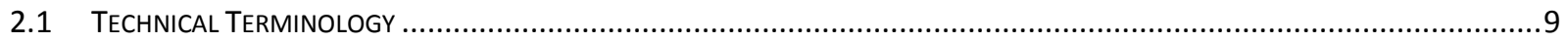

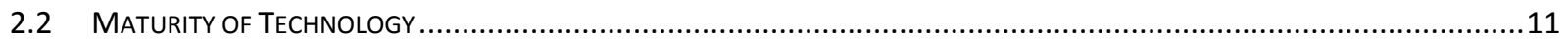

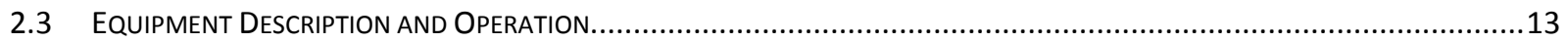

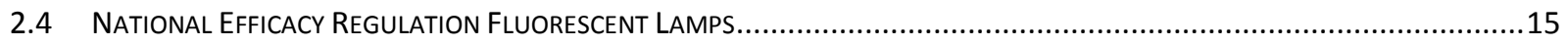

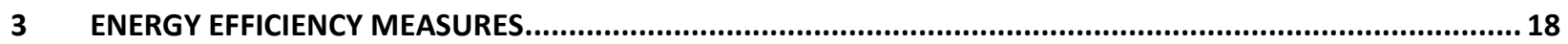

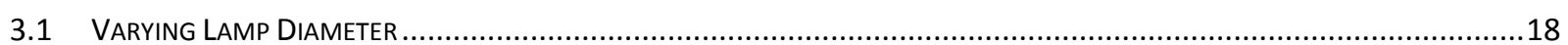

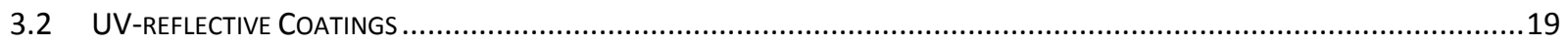

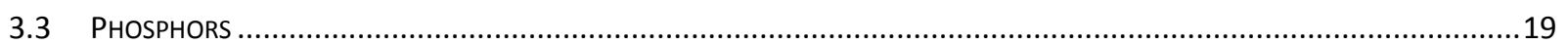

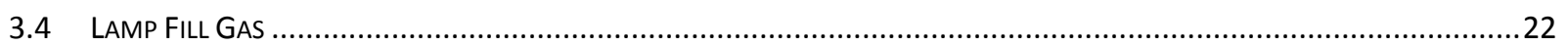

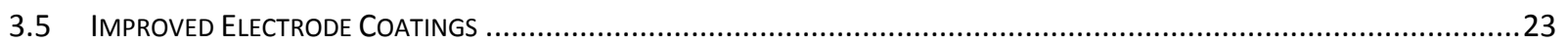

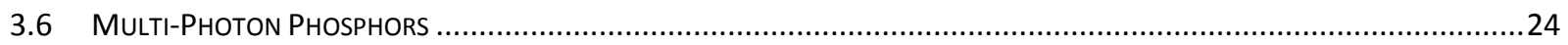

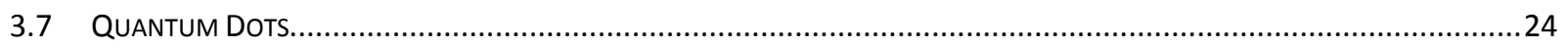

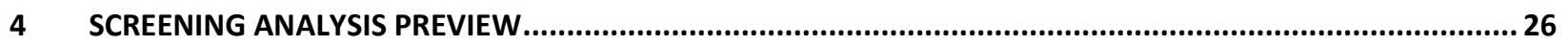

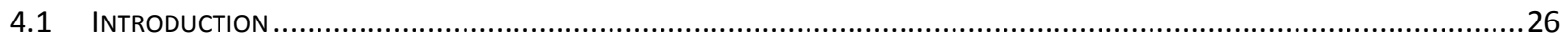

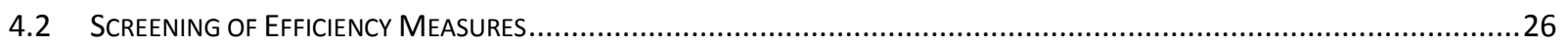

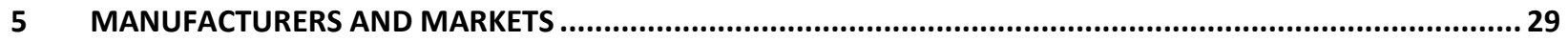

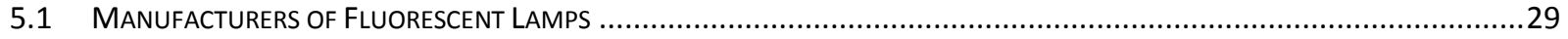

5.2 MARKET SIZE AND SHIPMENTS.

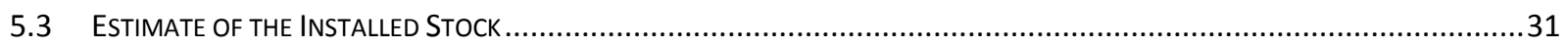

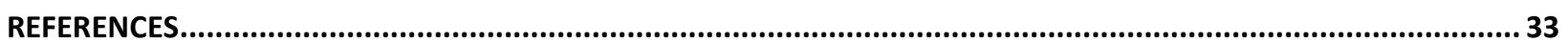

\section{List of Tables}

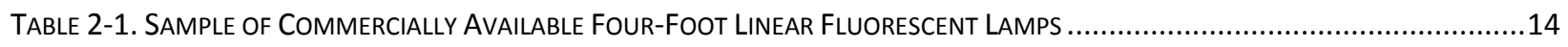

TABLE 2-2. US DOE MinIMUM EfFICACY StANDARDS FOR GENERAL SERVICE FLUORESCENT LAMPS ..........................................17

TABle 3-1. Chemical CoMposition of CoMmon RARE EARTH PHOSPHORS ..................................................................21

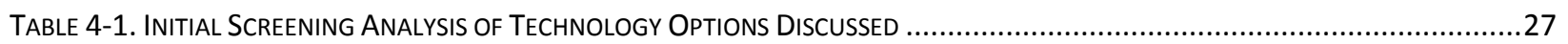

TABLE 5-1. US SHIPMENTS PROVIDED BY NEMA FOR EIGHT COMMON FLUORESCENT LAMP TYPES .............................................30

TABLE 5-2. US ShIPMENTS ESTIMATE PROJECTION BASED on NEMA's 2001-2005 DATA...................................................30

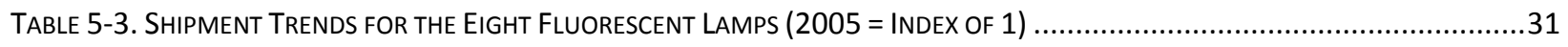

TABLE 5-4. ESTIMATED INSTALLED STOCK OF FLUORESCENT LAMPS IN THE US MARKET (000 UNITS) .........................................32

\section{List of Figures}

Figure ES-1. EfFICACY PROgRESSION Of FLUORESCENT LAMPS, 1936-2010 ..............................................................

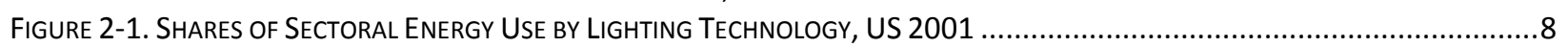

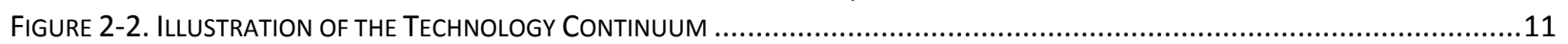

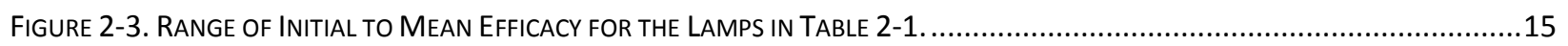

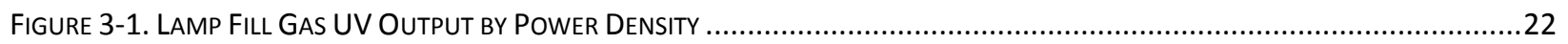




\section{List of Acronyms}

$\begin{array}{ll}\text { ANSI } & \text { American National Standards Institute } \\ \text { CCT } & \text { Correlated Color Temperature } \\ \text { CFL } & \text { Compact Fluorescent Lamp } \\ \text { CRI } & \text { Color Rendering Index } \\ \text { DOE } & \text { Department of Energy } \\ \text { EU } & \text { European Union } \\ \text { GE } & \text { General Electric } \\ \text { HID } & \text { High Intensity Discharge } \\ \text { LED } & \text { Light Emitting Diode } \\ \text { LLD } & \text { Lamp Lumen Depreciation } \\ \text { LPW } & \text { Lumens Per Watt } \\ \text { NEMA } & \text { National Electrical Manufacturers Association } \\ \text { US } & \text { United States } \\ \text { UV } & \text { Ultra Violet }\end{array}$




\section{Executive Summary}

Fluorescent lamps are the most widely used artificial light source today, responsible for approximately $70 \%$ of the lumens delivered to our living spaces globally. The technology was originally commercialized in the 1930's, and manufacturers have been steadily improving the efficacy of these lamps over the years through modifications to the phosphors, cathodes, fill-gas, operating frequency, tube diameter and other design attributes.

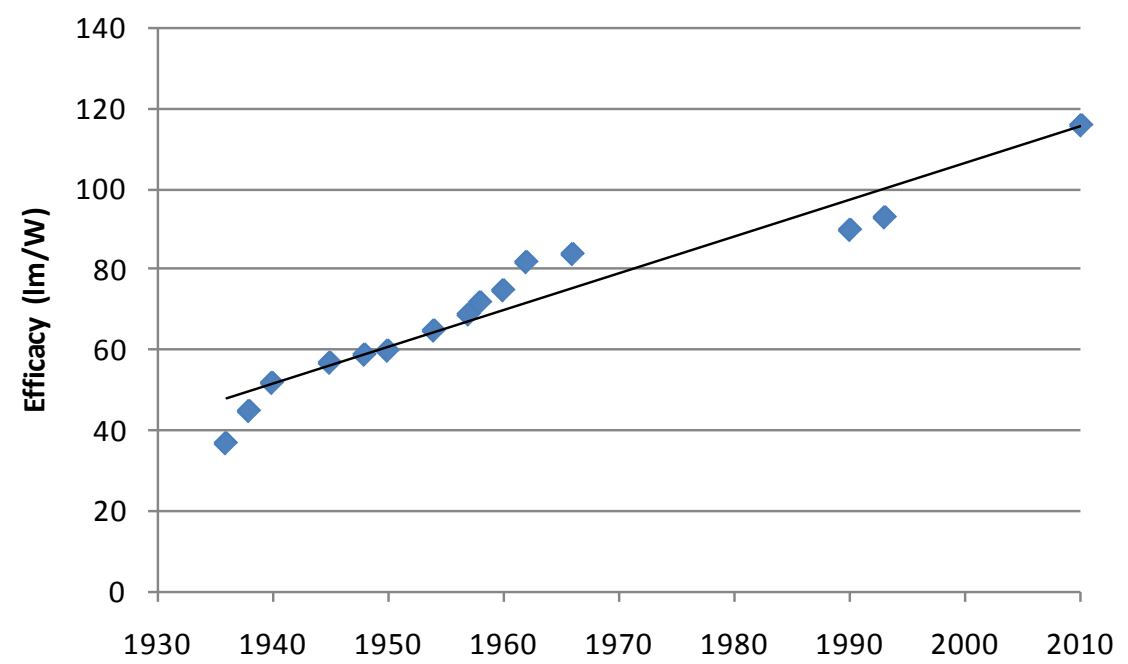

Figure ES-1. Efficacy Progression of Fluorescent Lamps, 1936-2010

Sources: Betz, 1993; Lighting Handbook; Lamp Manufacturer Catalogues

The most efficient commercially available fluorescent lamp is the 25 Watt T5 lamp. ${ }^{1}$ This lamp operates at 114-116 lumens per watt while also providing good color rendering and more than 20,000 hours of operating life. Industry experts interviewed indicated that while this lamp is the most efficient in the market today, there is still a further 10 to $14 \%$ of potential improvements that may be introduced to the market over the next 2 to 5 years. These improvements include further developments in phosphors, fill-gas, cathode coatings and ultraviolet (UV) reflective glass coatings. The commercialization of these technology improvements will combine to bring about efficacy improvements that will push the technology up to a maximum 125 to 130 lumens per watt.

One critical issue raised by researchers that may present a barrier to the realization of these improvements is the fact that technology investment in fluorescent lamps is being reduced in order to prioritize research into light emitting diodes (LEDs) and ceramic metal halide high intensity discharge (HID) lamps. Thus, it is uncertain whether these potential efficacy improvements will be developed, patented and commercialized. The emphasis for premium efficacy will continue to focus on T5 lamps, which are expected to continue to be marketed

\footnotetext{
${ }^{1}$ The Philips product (114 lm/W) called the "Master TL5 HE Eco"; the Osram product (116 lm/W) is called the "Lumilux T5 HE ES High Efficiency Energy Saver”; and General Electric has a 26 watt T5 lamp (111 lm/W) called the "T5 High Efficiency Watt Miser". All efficacy measurements are initial, taken at $35^{\circ} \mathrm{C}$ and at high frequency.
} 
along with the T8 lamp. Industry experts highlighted the fact that an advantage of the T5 lamp is the fact that it is $40 \%$ smaller and yet provides an equivalent lumen output to that of a T8 or T12 lamp. Due to its smaller form factor, the T5 lamp contains less material (i.e., glass, fill gas and phosphor), and has a higher luminance, enabling fixtures to take advantage of the smaller lamp size to improve the optics and provide more efficient overall system illuminance.

In addition to offering the market a high-quality efficacious light source, another strong value proposition of fluorescent lighting is its long operating life. In today's market, one manufacturer is offering fluorescent lamps that have a rated life of 79,000 hours - which represents 18 years of service at 12 hours per day, 365 days per year. These lamps, operated using a long-life ballast specified by the manufacturer, take advantage of improvements in cathode coatings, fill gas chemistry and pressure to extend service life by a factor of four over conventional fluorescent lamps. It should be noted that this service life is also longer (approximately twice as long) as today's high-quality LED products.

The fluorescent market is currently focused on the T5 and T8 lamp diameters, and it is not expected that other diameters would be introduced. Although T8 is a more optimal diameter from an efficacy perspective, the premium efficiency and optimization effort has been focused on T5 lamps because they are $40 \%$ smaller than T8, and are designed to operate at a higher temperature using high-frequency electronic ballasts. The T5 lamp offers savings in terms of materials, packaging and shipping, as well as smaller fixtures with improved optical performance.

Manufacturers are actively researching improvements in four critical areas that are expected to yield additional efficacy improvements of approximately 10 to 14 percent over the next five years, ultimately achieving approximately 130 lumens per watt by 2015. The active areas of research where these improvements are anticipated include:

- $\quad$ Improved phosphors which continue to be developed and patented, enabling higher efficacies as well as better color rendering and lumen maintenance;

- $\quad$ Enhanced fill gas - adjusting proportions of argon, krypton, neon and xenon to optimize performance, while also minimizing the mercury dose;

- $\quad$ Improved cathode coatings to enhance electron emissivity and extend lamp life; and

- UV-reflective glass coatings deposited between the layer of phosphor and the glass tube, to reflect any UV light back into the phosphor layer for down-conversion. 


\section{Introduction}

Lawrence Berkeley National Laboratory (LBNL) recently conducted a study, entitled Max Tech and Beyond: Maximizing Appliance and Equipment Efficiency by Design, to assess the maximum and projected efficiency of a number of different energy using technologies and products (Desroches \& Garbesi 2011). The study takes 'max tech' (maximum technologically feasible) appliance efficiency engineering analysis as a starting point and creates an expanded catalogue of technology options for a wide range of appliances, equipment and systems. This report was prepared as part of that effort, focusing on linear fluorescent lamps. This report takes into consideration the premium efficiency of products globally, the R\&D pathway, and information on prototype and design concepts under consideration that might further improve product efficiency.

Through this global study of fluorescent lamp efficacy, this research will address both the maximum energy-efficiency levels achieved in the markets today and discuss technical innovations under development by industry and academia. The findings from this study cover both the maximum technologically feasible performance available today for fluorescent lamps and the anticipated performance improvements that will be realized in the coming years. 


\section{Context and Background}

Fluorescent lamps are used widely in the commercial and industrial sectors in the United States. They constitute the primary light source for both of these sectors, and represent the largest electricity consumer for lighting (DOE, 2001). Fluorescent lamps are inexpensive to purchase and operate, and thus are widely used for general illumination applications such as officelighting, retail lighting and factory lighting. Due to their popularity in the market - and the awareness of these end-use sectors to life-cycle costs - fluorescent lamp technology has continued to advance over the years through research efforts to improve performance and efficacy. Compared to other light sources, fluorescent lamps offer one of the lowest life-cycle cost delivered lumen-hours of light, which makes them an attractive light source for many enduse applications.

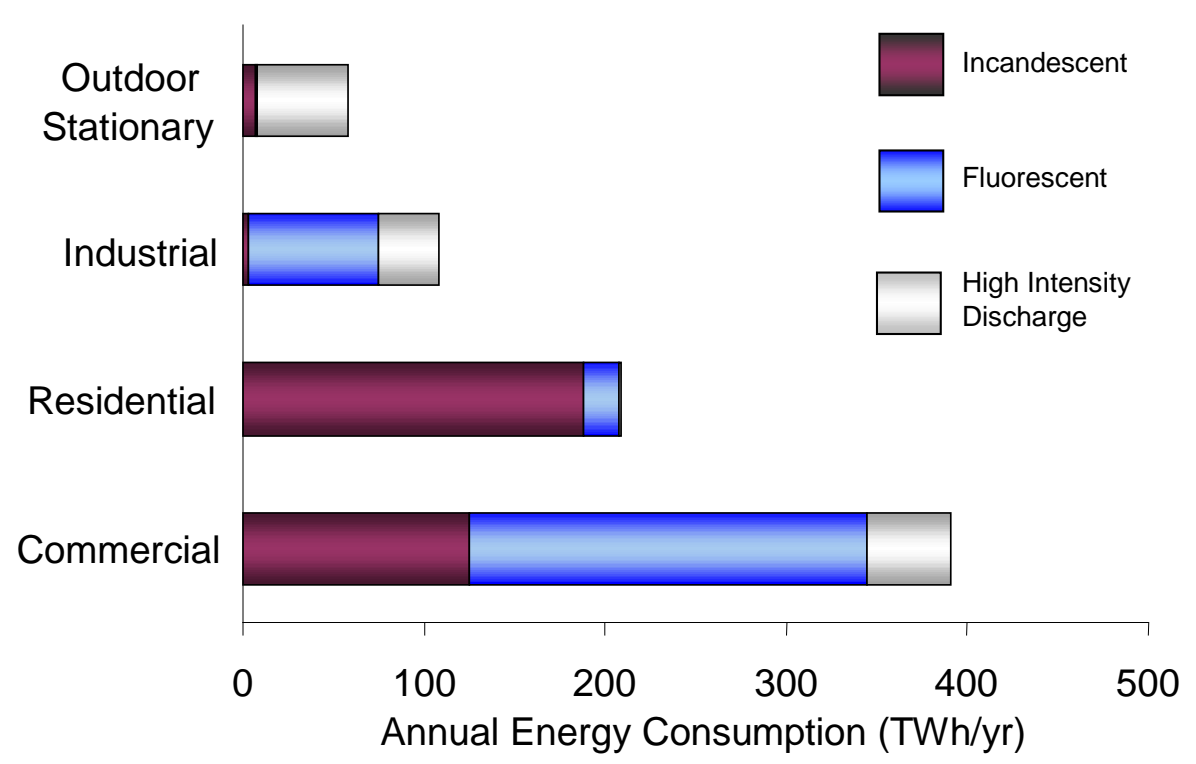

Figure 2-1. Shares of Sectoral Energy Use by Lighting Technology, US 2001

Source: NCI, U.S. Lighting Market Characterization Volume I: National Lighting Inventory and Energy Consumption Estimate, 2002.

A number of inventors are named as key contributors to the development of a practical, commercially available fluorescent lamp, including Peter Cooper Hewitt, Edmund Gremer and George Inman. General Electric is generally credited with being responsible for bringing the practical fluorescent lamp to market in the 1930's. This new technology was rapidly adopted, and by the early 1950's, fluorescent lamps were responsible the majority of lighting service delivered in the US. That is still the case today, with over $70 \%$ of the lumens delivered to our living spaces being derived from fluorescent sources. There are a wide variety of fluorescent lamps available now, produced by numerous companies around the world.

A fluorescent lamp is a gas discharge light source that converts ultra-violet (UV) radiation produced by an electrical arc inside the tube into white light. The arc discharge ionizes mercury vapor, which causes the emission of UV radiation having peak emission points of $185 \mathrm{~nm}$ and $254 \mathrm{~nm}$. Phosphors, coating the inside surface of the tube wall, absorb and convert the UV radiation into visible light (i.e., falling between 380 to $780 \mathrm{~nm}$ ). The arc discharge inside the 
lamp can be initiated and maintained in one of two ways - through voltage or magnetic induction. The more common method is to impose a voltage between electrodes, where an arc is created between two coiled tungsten wire electrodes. A mixture of alkaline earth oxides (i.e., barium oxide, strontium oxide, and calcium oxide) coats the tungsten wires to enhance electron emission. Initiation of the arc causes a small part of the emissive coating to be lost (i.e., sputtered), which affects the operating life of the lamp.

There are several areas of research which impact the efficacy of fluorescent lamps and can result in improved performance, such as the lamp operating frequency, the lamp diameter, the phosphor mix, the cathodes, the fill-gas and the pressure inside the tube. Each of these research areas are discussed in this report.

\subsection{Technical Terminology}

This section identifies and defines some terms and concepts that are related to the fluorescent lamp review and measures that will improve their efficacy.

- Ballast - a device used to obtain the necessary electrical conditions to start and operate an electric-discharge lamp, including a fluorescent lamp.

- Ballast factor - a measure of the lumen output for a specific lamp-ballast system relative to the rated lumen output measured with a reference ballast under standard ANSI test conditions. Ballast factor is not a measure of efficiency, although a lower ballast factor reduces lamp lumen output, it also consumes less input power.

- $\quad$ Ballast efficiency factor - is the ballast factor (defined above) divided by the input power of the ballast. The higher the BEF (for the same lamp-ballast combination) the more efficient the ballast.

- Color rendering index - is a measurement of a light source's ability to render colors accurately. A perfect rendering of color compared with the incandescent reference source is given a maximum value of 100. A limitation of this metric is that it is only applicable to light sources of the same correlated color temperature (CCT). In other words, CRI values of two light sources with different CCT cannot be compared.

- Correlated color temperature - the temperature of a blackbody ${ }^{2}$ radiator whose chromaticity most nearly resembles that of the light source. The metric for CCT is given in degrees Kelvin (K). Cooler temperatures (less than 3200K) are referred to as being "warm" in color as they contain more red light, while higher temperatures (in excess of 4000K) are referred to as being "cool” in color as they contain more blue light.

\footnotetext{
${ }^{2}$ Blackbody is defined as a temperature radiator of uniform temperature whose radiant excitance in all parts of the spectrum is the maximum obtainable from any temperature radiator at the same temperature. Such a radiator is called a blackbody because it absorbs all the radiant energy that falls upon it.
} 
- $\quad$ Efficacy - the measured visible light output of a lamp in lumens divided by the measured electrical power input in watts, expressed in lumens per watt (LPW). Efficacy provides a metric to compare the efficiency of white-light sources, although it does not account for ballast losses in the fluorescent lighting system.

- $\quad$ Fixture - the housing into which a lamp and ballast are installed to create a finished luminaire. The fixture protects the lamp, and generally contains a socket(s) into which the lamp is inserted and usually manages or directs light distribution from the lamp.

- $\quad$ Fluorescent lamp - a low pressure mercury electric-discharge lamp in which a phosphor-coating transforms a portion of UV energy generated by a mercury discharge into visible light.

- $\quad$ Foot-candle - a measure of illuminance equal to one lumen per foot square or 10.76 lux. One foot-candle is equivalent to the amount of light emitted by a single candle onto a plane orthogonal to the angle of incidence at a distance of one foot from the candle.

- Illuminance - is the density of luminous flux incident on an area. In other words, illuminance is the density of light determined by taking the total amount of light that falls on a plane divided by the total area of the plane.

- Induction lamp - a fluorescent lamp where the electric discharge is induced by a magnetic field; thus an induction lamp is a fluorescent lamp without any electrodes.

- Lamp lumen depreciation - the intrinsic reduction in light output over the operating lifetime of a lamp, caused in part by non-recoverable factors such as the loss of emissive material on the electrodes, deposits of sputtered material on the inside of the glass tube and the leakage of fill gas.

- $\quad$ Light - radiant energy that is capable of exciting the retina and producing a visual stimulation. Since the energy at each wavelength (i.e., visible light color) does not stimulate the human eye equally, to convert radiant energy to useful light for the human eye, each wavelength is weighted by the eye's sensitivity function, $\mathrm{V}(\lambda)$.

- $\quad$ Lumen - the metric unit of luminous flux, defined photometrically as the luminous flux emitted within a unit solid angle (one steradian) by a point source having a uniform luminous intensity of one candela. A lumen measures the radiometric energy emitted from a light source weighted by the human eye's sensitivity function, $V(\lambda)$.

- $\quad$ Luminaire - a complete lighting unit consisting of a lamp or lamps and ballast(s) (when applicable) together with a fixture (optics, housing and parts) designed to distribute the light, to position and protect the lamps, and to connect the lamps to the power supply. 
- $\quad$ Rated life - under standard testing conditions, the time at which 50 percent of a large sample of fluorescent lamps no longer operate (i.e., cease producing light).

- $\quad$ Spectral power distribution - a pictorial representation of the radiant power emitted by a light source at each wavelength or band of wavelengths in the visible region of the electromagnetic spectrum (380 to 780 nanometers). The SPD determines the CCT and CRI of the light source, and indicates the perceived color and quality of the light generated by the lamp.

- $\quad$ System efficacy - measurement of the overall energy performance of lamp-ballast combinations, calculated by multiplying the rated lamp lumens by the ballast factor and dividing the product by total input watts. The application of system efficacy is the same as for lamp efficacy, except that it takes into account the contribution of the ballast as it delivers power to the lamp from the main electricity supply.

\subsection{Maturity of Technology}

One critical facet of a technology being considered in this study is how close that technology is to commercialization. The graphic below represents a technology continuum, used to classify a product and thus enable planning, including technical and business actions and decisions that are necessary to move a concept from a scientific phenomenon to a marketable product. In order for a technology to advance to the next stage along the continuum, it must meet criteria at each stage.

The technology continuum is divided into seven technology maturity stages described below. Figure 2-2 presents the seven technology maturity stages that comprise the technology maturity continuum. This graphic is developed for each of the technology options discussed in this chapter, with the gray diamond representing the stage for each technology option. In the example shown below, a given technology is classified as being at the Engineering Development stage.

\section{Figure 2-2. Illustration of the Technology Continuum}

\begin{tabular}{|c|c|c|c|c|c|c|}
\hline \multicolumn{7}{|c|}{ Technology Maturity Stage } \\
\hline $\begin{array}{c}\text { Basic Science } \\
\text { Research }\end{array}$ & $\begin{array}{c}\text { Applied } \\
\text { Research }\end{array}$ & $\begin{array}{c}\text { Exploratory } \\
\text { Development }\end{array}$ & $\begin{array}{c}\text { Advanced } \\
\text { Development }\end{array}$ & $\begin{array}{c}\text { Engineering } \\
\text { Development }\end{array}$ & $\begin{array}{c}\text { Product } \\
\text { Demonstration }\end{array}$ & $\begin{array}{c}\text { Commercialization } \\
\text { and Sales }\end{array}$ \\
\hline & & & & & & \\
& & & & & & \\
\hline
\end{tabular}

The following text provides a brief description of each technology maturity stage:

- $\quad$ Basic Science Research - Fundamental science exploration is performed to expand the knowledge-base in a given field. Scientific principles (with data-empirical and/or theoretical derivation) are formulated and proven. The output from these projects would generally be peer-reviewed papers published in recognized scientific journals. Specific applications are not necessarily identified at this stage. 
- $\quad$ Applied Research - Scientific principles are demonstrated, an application is identified, and the technology shows potential advantages in performance over commercially available technologies. Laboratory testing and/or math modeling is performed to identify the application(s), or provide the options (technical pathways) to an application. Testing and modeling add to the knowledge base that supports an application and point to performance improvements.

- $\quad$ Exploratory Development - A product concept addresses an energy efficiency priority. From laboratory performance testing, down select from alternative technology approaches for best potential performance, via selection of materials, components, processes, cycles, and so on. With laboratory performance testing data, down select from a number of market applications to the initial market entry ideas. This product concept must exhibit cost and/or performance advantages over commercially available technologies. Technical feasibility should be demonstrated through component bench-scale testing with at least a laboratory model of the concept.

- $\quad$ Advanced Development - Product concept testing is performed on a fully functional laboratory prototype - "proof of design concept" testing. Testing is performed on prototypes for a number of performance parameters to address issues of market, legal, health, safety, etc. Through iterative improvements of concept, specific applications and technology approaches are refocused and "down selected." Product specification (for manufacturing or marketing) is defined. Technology should identify clear advantages over commercially available technologies, and alternative technologies, from detailed assessment.

- $\quad$ Engineering Development - "Field ready prototype" system is developed to refine product design features and performance limits. Performance mapping is evaluated and testing of a field-ready prototype/system is carried out in a representative or actual application with a small sample in the field. The number of units is a function of unit cost, market influences, monitoring costs, owner/operator criteria, etc. Feedback from the user and technical data gathered from field trials are used to improve prototype design. Further design modifications and re-testing are performed as necessary.

- Product Demonstration - Operational evaluation of the demonstration units in the field is conducted to validate performance as installed. Third party monitoring of the performance data is required, although less data is recorded relative to the "field ready prototype" test in the previous stage. Pre-production units may be used. Size of demo is a function of unit cost, monitoring cost, etc., and involves relatively more visibility.

- Commercialization and Sales - The product is commercialized and is actively being marketed to customers. 


\subsection{Equipment Description and Operation}

A fluorescent lamp is a light source that emits visible light when operated on a ballast. The lamp itself consists of a glass tube filled with mercury vapor and an inert gas or gases (usually includes argon). The tube is sealed at each end, and the inside surface of the tube is coated with phosphor. There are coiled, coated tungsten filaments at each end of the tube called cathodes which emit large quantities of electrons when voltage is applied to the lamp and it reaches operating temperature. In the electrical arc created between the cathodes, the electrons collide with mercury atoms in the fill-gas, raising their energy state. As the mercury atoms return to their stable state, they emit UV light. This UV light is then adsorbed and down-converted by the phosphor coating, being re-emitted as visible white-light.

The electrical energy delivered to the fluorescent lamp is converted into other forms of energy, including UV radiation and heat. For a conventional fluorescent lamp, the breakdown of energy is as follows: $65 \%$ is converted into UV radiation, which is used to excite the phosphor layer in the lamp. Approximately $26 \%$ is converted into heat through elastic collisions that do not yield UV radiation; $6 \%$ is converted into visible radiation (inside the tube) and $3 \%$ of the energy is lost in the electrode. And, of the $65 \%$ of UV radiation, approximately $40 \%$ is converted into visible radiation. Therefore, on an overall system basis, approximately $23 \%$ of the electrical energy supplied to a fluorescent lamp is emitted as visible light and approximately $77 \%$ is converted to waste heat.

Fluorescent lamps are always operated with a current-limiting device known as a ballast. In addition to limiting current, the ballast is also responsible for starting the lamp, and supplying the voltage to initiate and maintain the arc. In general, there are three types of ballasts programmed start, instant start and rapid start. Manufacturers recommend matching the fluorescent lamp type to the ballast - i.e., installing an instant start lamp in a fixture that has an instant start ballast - and thus the fluorescent lamp base socket is often changed to ensure the lamps are used correctly. Typically, instant start ballasts have single-pin sockets and rapid start and programmed start ballasts have two-pin sockets.

The efficiency of a fluorescent lamp is measured in lumens of visible light divided by the watts of power consumed by the lamp. This metric is called the "efficacy" of the lamp, and is presented in lumens per watt. Fluorescent lamp efficacy varies with the operating frequency and shape / diameter of the fluorescent tube itself, but generally is around 70 lumens per watt for the least efficient and 110 lumens per watt for the most efficient. By comparison, a typical incandescent general service lamp is around 15 lumens per watt - a factor of 5 to 7 times lower.

Practical fluorescent lamps were first introduced into the market in the 1930's, and today are manufactured in a variety of shapes and sizes. The light output from fluorescent lamps has improved over this time period, with products offering a broad range of correlated color temperatures (CCT) and color rendering indexes (CRI) for a variety of applications.

The following table depicts some of the aforementioned commercially available fluorescent lamps and typical performance levels of these lamps, holding the CCT and length approximately constant. The lumens (i.e., light output) column is presented with two values - the initial lumens emitted by the lamp when first used and the mean lumens when the lamp is halfway through its 
rated life. The manufacturer literature underpinning this table shows that the mean efficacy values are only 5 and 10\% lower than the initial efficacy values - being highest for T12 (10\%) and lowest for T8 (5\%). The initial efficacy values range from around 70 lumens per watt for a high-output T12 lamp to 111 lumens per watt for a T5 ultra efficient lamp - an improvement in efficacy of $57 \%$.

Table 2-1. Sample of Commercially Available Four-Foot Linear Fluorescent Lamps

\begin{tabular}{|c|c|c|c|c|c|c|c|c|}
\hline Type & Base & $\begin{array}{c}\text { Power } \\
\text { (watts) }\end{array}$ & $\begin{array}{c}\text { Length } \\
\text { (inches) }\end{array}$ & $\begin{array}{c}\text { Life } \\
(\mathbf{1 0 0 0} \mathbf{h r s})\end{array}$ & $\begin{array}{c}\text { CCT } \\
\left({ }^{\circ} \mathbf{K}\right)\end{array}$ & CRI & $\begin{array}{c}\text { Lumens } \\
\text { (initial/mean) }\end{array}$ & $\begin{array}{c}\text { Efficacy } \\
\left(\text { Im/ } \mathbf{W}_{\text {nom }}\right. \\
\text { initial/mean })\end{array}$ \\
\hline T5 & G5 & 28 & 45.2 & $30-36$ & 4100 & 85 & $2900 / 2660$ & $103.6 / 95.0$ \\
\hline T5-Miser & G5 & 26 & 45.2 & $25-30$ & 4100 & 85 & $2900 / 2660$ & $111.5 / 102.3$ \\
\hline T5HO & G5 & 54 & 45.2 & $30-36$ & 4100 & 85 & $5000 / 4600$ & $92.6 / 85.2$ \\
\hline T5HO-Miser & G5 & 51 & 45.2 & $30-36$ & 4100 & 85 & $5000 / 4600$ & $98.0 / 90.2$ \\
\hline T8 & G13 & 32 & 48.0 & $30-36$ & 4100 & 86 & $2950 / 2800$ & $92.2 / 87.5$ \\
\hline T8-LL & G13 & 32 & 48.0 & $40-46$ & 4100 & 81 & $2850 / 2675$ & $89.1 / 83.6$ \\
\hline T8-Miser & G13 & 25 & 48.0 & $40-46$ & 4100 & 85 & $2500 / 2350$ & $100.0 / 94.0$ \\
\hline T8-Ultramax & G13 & 28 & 48.0 & $36-42$ & 4100 & 82 & $2725 / 2562$ & $97.3 / 91.5$ \\
\hline T12-Miser & G13 & 34 & 48.0 & 20 & 4100 & 82 & $2900 / 2610$ & $85.3 / 76.8$ \\
\hline T12 & G13 & 40 & 48.0 & 20 & 4100 & 80 & $3350 / 3050$ & $83.8 / 76.3$ \\
\hline T12-LL & G13 & 40 & 48.0 & 24 & 4100 & 80 & $3400 / 3060$ & $85.0 / 76.5$ \\
\hline T12HO & R17d & 60 & 48.0 & 12 & 4100 & 72 & $4250 / 3830$ & $70.8 / 63.8$ \\
\hline
\end{tabular}

Source: General Electric Lamp and Ballast Catalogue, Fluorescent Section updated November 2011.

Taking just the initial and median efficacy values from the table above and plotting them for each of the fluorescent lamps shown, the following graph is prepared showing the lumen maintenance values for each lamp. Due to the fact that these are all fluorescent lamps, the lumen maintenance of each lamp is similar across all the lamp shapes and types. Other lamp types with greater lumen depreciation over their operating lifetimes (e.g., mercury vapor high intensity discharge lamps) would exhibit a longer line due to the significant difference between initial and mean lumens. 


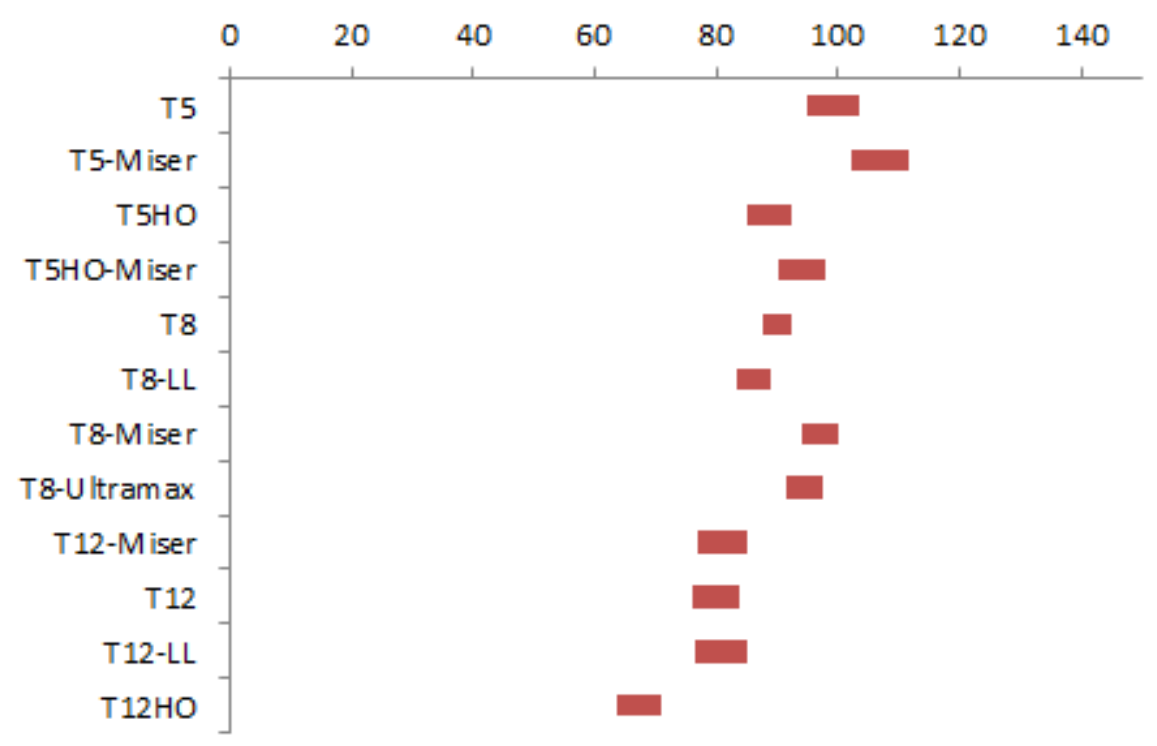

Figure 2-3. Range of Initial to Mean Efficacy for the Lamps in Table 2-1.

In chapter 3 of this report, the methods developed and applied by manufacturers to improve the efficacy (i.e., lumens of visible light per watt of power consumed) of fluorescent lamps are discussed.

\subsection{National Efficacy Regulation Fluorescent Lamps}

The US Department of Energy (DOE) has mandatory regulatory standards for general service fluorescent lamps, which sets standards for certain high-volume fluorescent lamps. In July 2009, the US DOE issued revised energy conservation standards for general-service fluorescent lamps. ${ }^{3}$ These regulations will apply to lamps manufactured after July 14, 2012 and will eliminate the least efficient fluorescent lamps from the market.

In that same July 2009 Final Rule, DOE expanded its scope of coverage to include the following fluorescent lamps and wattages that were previously not covered:

- 2-foot, medium bipin U-shaped lamps ${ }^{4}$ that are 25 to 28 watts inclusive;

- 4-foot, medium bipin lamps that are 25 to 28 watts inclusive;

- 4-foot T5, miniature bipin, straight-shaped, standard output lamps, 26 watts or greater;

- 4-foot T5, miniature bipin, straight-shaped, high output lamps, 49 watts or greater;

- 8-foot recessed double contact, rapid start, HO lamps other than those in ANSI C78.1$1991 ;$

\footnotetext{
${ }^{3}$ Energy Conservation Program: Energy Conservation Standards and Test Procedures for General Service Fluorescent Lamps and Incandescent Reflector Lamps, Docket Number EE-2006-STD-0131 / RIN 1904-AA92, 74 FR 34080, Tuesday, July 14, 2009.

${ }^{4}$ The length of these U-shaped lamps is stated to be nominally 2-foot although these lamps are 22 to 25 inches in length.
} 
- 8-foot recessed double contact, rapid start, HO lamps (other than 0.800 nominal amperes) defined in ANSI C78.1-1991; and

- 8-foot single pin instant start slimline lamps that are 52 watts or greater, and which are not defined in ANSI C78.3-1991.

With these newly covered lamps and the ones previously covered by EPCA, the following list shows all the covered general service fluorescent lamps in the U.S. relative to the range of some of the fluorescent lamps offered in manufacturers catalogues (note: this does not include compact fluorescent lamp types). Under each of the types of fluorescent lamps, there is a " $\mathrm{T}$ " designation which denotes the cross-section diameter of the fluorescent tube in eighths of an inch. The lamps are manufactured in a range of different lengths, which are given in inches for each $\mathrm{T}$ designation. Those lamp types, diameters and lengths that are highlighted in red and underlined are lamps either currently covered or that will be covered from July 14, 2012. The lamp types, diameters and lengths which are not highlighted are sold in the US market but are not covered by DOE (i.e., these lamps are not subject to regulation).

- "Regular"-Linear

o T5: 21.6”, 33.4”, 45.2”, 48”, 57.1”, 60” Mini BiPin (G5)

o T8: 18”, 24”, 36”, 40”, 48”, 60”, 70”, 72” Medium BiPin (G13)

o T12: 36”, 48”, 96”Medium BiPin (G13)

- Instant Start-Linear

o T6: 42”, 64”, 72” Single Pin (Fa8)

o T8: 24”; 48”, 60”, 70”, 72”, 96" Single Pin (Fa8)

o T12: 24”, 36”, 42”, 48”, 60”, 64”, 72”, 84”, 96” Single Pin (Fa8)

o T17: 60" Mogul BiPin (G20)

- High Output-Linear

o T5: 21.6”, 33.4”, 34”, 36”, 45.2”, 46”, 48”, 57.1”, 58”, 60” Mini BiPin (G5)

o T8: 48”, 60”, 72”, 96" RDC (R17d)

o T12: 18”, 24”, 30”, 36”, 42”, 48”, 60”, 64”, 72”, 84”, 86”, 96” RDC (R17d)

o PG17: 96"

- Very High Output-Linear

o T10: 48”, 60”, 72” RDC (R17d)

o T12: 24”, 48”, 60”, 72”, 96” RDC (R17d)

- U-Shaped

o T8: 1-5/8” spacing: 22-25” Medium BiPin (G13)

o T8: 6" spacing: 22-25" Medium BiPin (G13)

o T12: 3-5/8” spacing: 22-25" Medium BiPin (G13)

o T12: 6” spacing: 22-25” Medium BiPin (G13)

- Circline Lamps

o T5: $11.54 ” 2 \mathrm{GX} 13$

o T9: 6.5”, 8”, 8.25”, 11.5”, 12”, 15.5”, 16” 4-pin (G10q)

Congress originally established energy conservation standards on general-service fluorescent lamps in the Energy Policy Act of 1992. DOE's new regulations expand the scope of coverage for these regulations by adding 8 foot T8 lamps, 4 foot T5 lamps and a broader range of wattages for 4 foot T8 and T12 lamps. The regulation also increases the efficacy requirements for each lamp type, and creates separate requirements for the standard correlated color temperatures and high correlated color temperatures. The new lamp standards are summarized in the table below. Products failing to achieve the new standards will be prohibited from sale in the United States. 
Table 2-2. US DOE Minimum Efficacy Standards for General Service Fluorescent Lamps

\begin{tabular}{|l|c|c|}
\hline \multicolumn{1}{|c|}{ Type of Fluorescent Lamp } & Correlated Color Temperature & $\begin{array}{c}\text { Minimum Average Lamp } \\
\text { Efficacy (lm/W) }\end{array}$ \\
\hline \multirow{2}{*}{ 4-foot medium bipin, $\geq 25 \mathrm{~W}$} & $\leq 4,500 \mathrm{~K}$ & 89 \\
\cline { 2 - 3 } & $>4,500 \mathrm{~K}$ and $\leq 7,000 \mathrm{~K}$ & 88 \\
\hline \multirow{2}{*}{ 2-foot U-shaped, $\geq 25 \mathrm{~W}$} & $\leq 4,500 \mathrm{~K}$ & 84 \\
\cline { 2 - 3 } & $>4,500 \mathrm{~K}$ and $\leq 7,000 \mathrm{~K}$ & 81 \\
\hline \multirow{2}{*}{ 8-foot slimline, $\geq 52 \mathrm{~W}$} & $\leq 4,500 \mathrm{~K}$ & 97 \\
\cline { 2 - 3 } & $>4,500 \mathrm{~K}$ and $\leq 7,000 \mathrm{~K}$ & 93 \\
\hline 8-foot high output & $\leq 4,500 \mathrm{~K}$ & 92 \\
\hline \multirow{2}{*}{$\begin{array}{l}\text { 4-foot (T5) miniature bipin } \\
\text { standard output, } \geq 26 \mathrm{~W}\end{array}$} & $>4,500 \mathrm{~K}$ and $\leq 7,000 \mathrm{~K}$ & 88 \\
\hline \multirow{2}{*}{$\begin{array}{l}\text { 4-foot (T5) miniature bipin } \\
\text { high output, } \geq 49 \mathrm{~W}\end{array}$} & $\leq 4,500 \mathrm{~K}$ & 86 \\
\cline { 2 - 3 } & $>4,500 \mathrm{~K}$ and $\leq 7,000 \mathrm{~K}$ & 81 \\
\cline { 2 - 3 } & $\leq 4,500 \mathrm{~K}$ & 76 \\
\hline
\end{tabular}

The result of this regulatory standard is that the least-efficient and lowest-cost fluorescent lamps will be eliminated from the market-including:

- $\quad$ Most 4 foot linear and 2 foot U-shaped T12 lamps

- $\quad$ All 2 foot full-wattage and energy-saving U-shaped T12 lamps

- $\quad$ All 75W F96T12 and 110W F96T12HO lamps

- $\quad$ Most 60W F96T12/ES and 95W F96T12/ES/HO lamps

- $\quad$ All 4 foot 700-series rare-earth phosphor lamps rated at 2,800 lumens

- $\quad$ Certain 8 foot T8 slimline single-pin 700-series and 8 foot T8 HO recessed doublecontact base lamps

Starting on July 14, 2012, these lamps can no longer be manufactured for or imported into the US market, however wholesalers and distributors are allowed to continue selling their inventories until they are empty. 


\section{$3 \quad$ Energy Efficiency Measures}

\subsection{Varying Lamp Diameter}

The diameter of a fluorescent tube is one variable that affects the conversion efficiency of electrical energy into UV radiation, which is then converted by phosphors into visible light. The cross-sectional diameter of a fluorescent lamp influences the processes in the lamp's plasma, and ultimately the production of visible light. Inside the tube, the kinetic energy of an electron colliding with a neutral mercury atom raises the energy state of the mercury atom. After a short time, the mercury atom returns to the ground state with the energy difference normally radiated as a line-spectrum wavelength at $254 \mathrm{~nm}$ (i.e., in the UV region). This radiation emission, in turn, excites the phosphor coating on the inside wall of the fluorescent tube, which downconverts the UV light into visible light.

That said, if the excited atoms collide with other particles in the plasma before emitting this energy, this can result in a down-conversion of the radiation before it reaches the phosphor. In large diameter fluorescent lamps, the chance of multiple-collision down-conversions increases, and the emission of $254 \mathrm{~nm}$ UV light is reduced which in turn reduces light output. Alternatively, for smaller diameter lamps, the ratio of the tube circumference to cross-sectional area increases, along with the rate of electron and mercury ion extinction. This has the effect of increasing the energy-state of the electrons, which, if they become too high, will reduce the probability of exciting a mercury atom to the appropriate energy state for emitting UV radiation.

Thus, there is an optimum diameter for fluorescent lamps, which is different for phosphors designed to work with $185 \mathrm{~nm}$ UV radiation (i.e., rare-earth phosphors) and those designed to work with $254 \mathrm{~nm}$ UV radiation (i.e., calcium halophosphate phosphors). The optimum diameter for the halophosphates is slightly larger than that of the rare-earth phosphors, hence T8 (1" diameter) and T5 (5/8” diameter) lamps in North America are not manufactured with halophosphates. In the US market, halophosphates are only manufactured in the T12 (1-1/2” diameter) lamps. According to the Lighting Handbook of the Illuminating Engineering Society of North America, this corresponds to the optimal diameter of the lamp using this phosphor type.

Manufacturers interviewed thought that it would be unlikely that a new diameter fluorescent tube lamp will be introduced to the market in the next 5 to 10 years. Instead, the expectation is that the market will gradually shift from T12 to T8 and T5 lamps, through a combination of market forces and regulatory actions. T5 will continue to offer the highest efficacy of fluorescent lamps, while at the same time affording fluorescent luminaires with improved optics due to the smaller lamp diameter and higher surface luminance. A T5 lamp has approximately 60 percent of the surface area of a T8 lamp, however it has nearly the same light output (2900 vs. 2950 lumens) per lamp, thus luminaires designed for $\mathrm{T} 5$ lamps must be designed to avoid discomfort glare for occupants that may result from any direct view of the lamp.

Given the input that has been provided by industry, lamp diameter as an energy-efficiency measure has been assigned to the "Commercialization and Sales" category of the technology maturity continuum. While it is known that there are other diameters that may offer slightly more optimized lamp performance, this is unlikely to be realized in the market for two reasons: 1) industry is not prepared to make the large investment in this technology to re-tool for another 
lamp diameter and 2) industry has focused its efforts on the T5 and T8 lamps due to their smaller diameter and quantity of materials, the more compact size (saving on shipping and other costs) and improved optical performance.

\begin{tabular}{|c|c|c|c|c|c|c|}
\hline \multicolumn{7}{|c|}{ Technology Maturity Stage } \\
\hline $\begin{array}{c}\text { Basic Science } \\
\text { Research }\end{array}$ & $\begin{array}{c}\text { Applied } \\
\text { Research }\end{array}$ & $\begin{array}{c}\text { Exploratory } \\
\text { Development }\end{array}$ & $\begin{array}{c}\text { Advanced } \\
\text { Development }\end{array}$ & $\begin{array}{c}\text { Engineering } \\
\text { Development }\end{array}$ & $\begin{array}{c}\text { Product } \\
\text { Demonstration }\end{array}$ & $\begin{array}{c}\text { Commercialization } \\
\text { and Sales }\end{array}$ \\
\hline & & & & & & \\
& & & & & & \\
\hline
\end{tabular}

\subsection{UV-reflective Coatings}

The layer of phosphor lining the interior surface of a fluorescent lamp glass tube may allow some (small) portion of the UV radiation to pass through without converting it to visible light. To minimize this effect and improve the performance, the inside surface of the glass tube can be coated with a reflective coating that will reflect any UV radiation that passes through the phosphor back onto the phosphor, increasing the amount of UV radiation absorbed and converted into visible light. This coating is a refractory oxide, such as aluminum oxide $\left(\mathrm{Al}_{2} \mathrm{O}_{3}\right)$, silicon oxide $\left(\mathrm{SiO}_{2}\right)$, and titanium oxide $\left(\mathrm{TiO}_{2}\right)$. When a coating like this is used in conjunction with costly rare-earth phosphors, the thickness of the phosphor necessary to capture maximum UV radiation can be reduced. These coatings are used on commercially available lamps today, and researchers indicate that there is still room for improvement in the coatings and determining the optimal phosphor thickness for lamps that have the UV-reflective coating.

Given the input that has been provided by industry, UV-reflective coatings are already commercialized and are still undergoing improvement. For this reason, two diamonds are shown in the technology maturity continuum below, reflecting the fact that today's lamps incorporate this technology and that new and improved coatings are still being developed for manufacture.

\begin{tabular}{|c|c|c|c|c|c|c|}
\hline \multicolumn{7}{|c|}{ Technology Maturity Stage } \\
\hline $\begin{array}{c}\text { Basic Science } \\
\text { Research }\end{array}$ & $\begin{array}{c}\text { Applied } \\
\text { Research }\end{array}$ & $\begin{array}{c}\text { Exploratory } \\
\text { Development }\end{array}$ & $\begin{array}{c}\text { Advanced } \\
\text { Development }\end{array}$ & $\begin{array}{c}\text { Engineering } \\
\text { Development }\end{array}$ & $\begin{array}{c}\text { Product } \\
\text { Demonstration }\end{array}$ & $\begin{array}{c}\text { Commercialization } \\
\text { and Sales }\end{array}$ \\
\hline & & & & & & \\
\hline
\end{tabular}

\subsection{Phosphors}

The phosphor layer in a fluorescent lamp works to convert the UV radiation into visible "white" light. Phosphors have a range of conversion efficiencies, and with different materials they can convert UV radiation into longer wavelengths in the visible spectrum including blue, green and red light that blend together to form white light. This section discusses the technology behind phosphors and blends that will improve their performance. 
Phosphor deposits on the inside surface of a fluorescent tube have an optimum thickness. When the phosphor deposit is thinner than the optimum value, the phosphor will not absorb UV radiation sufficiently, and the lumen output of the lamp will be reduced. If however, the phosphor deposit is too thick, then some of the down-converted visible light will be re-absorbed in the phosphor layer or reflected back into the lamp, lowering lumen output. Thus, much like the diameter of the glass tube, there is an optimal thickness for phosphors with declining lamp performance above and below that thickness.

Research has found that light emission at wavelengths of 450, 540 and $610 \mathrm{~nm}$ enables good rendering of most colors (i.e., with a CRI greater than 80). Thus, phosphor researchers have worked toward producing phosphor materials that down-convert the UV-light emitted by the mercury atoms into three bands of light. In 1972, the phosphor blend consisted of a blueemitting phosphor at $450 \mathrm{~nm}$, a green-emitting phosphor at $525 \mathrm{~nm}$, and an orange-red emitting phosphor at $611 \mathrm{~nm}$, with a reported CRI of 83. While this was a good result, the phosphor was not commercialized because it did not maintain its performance over the lamp's entire operating life.

In 1974, a series of rare-earth ${ }^{5}$ activated aluminate phosphors were developed by J.M.P.J. Verstegen working at Philips Lighting. The luminous efficacy of these phosphors was comparable to halophosphate phosphors, and they had better color rendering. The phosphor mix contained three phosophors - Blue: $\mathrm{BaMg}_{2} \mathrm{Al}_{16} \mathrm{O}_{27}: \mathrm{Eu}^{2+}$, Green: $\mathrm{CeMgAl}_{11} \mathrm{O}_{19}: \mathrm{Tb}^{3+}$, and Red: $\mathrm{Y}_{2} \mathrm{O}_{3} \mathrm{Eu}^{3+}$. This phosphor mix was found to attain a very high color rendering value (i.e., 85 CRI) across a broad range of correlated color temperatures (i.e., 2500 to 6500K). More than 35 years later, improved versions of the blue and green phosphors have been developed, but the red phosphor originally developed is still the one commonly used in rare-earth tri-phosphor fluorescent lamps today. The table below presents the chemical composition of some of the triphosphors used, although the actual chemical composition and proportion of phosphors in lamps can vary by manufacturer and lamp type.

\footnotetext{
${ }^{5}$ The term "rare earth" phosphor refers to phosphor molecules that contain one or more rare earth elements in their chemical composition. The rare earth elements are a collection of seventeen elements in the periodic table, namely scandium (Sc), yttrium (Y), and the fifteen lanthanides: lanthanum (La), cerium (Ce), praseodymium ( $\mathrm{Pr}$ ), neodymium (Nd), promethium (Pm), samarium (Sm), europium (Eu), gadolinium (Gd), terbium (Tb), dysprosium (Dy), holmium (Ho), erbium (Er), thulium (Tm), ytterbium ( $\mathrm{Yb})$, and lutetium (Lu).
} 
Table 3-1. Chemical Composition of Common Rare Earth Phosphors

\begin{tabular}{|c|c|}
\hline Phosphor's Emission & Chemical Composition \\
\hline Blue & $\begin{array}{l}(\mathrm{Sr}, \mathrm{Ca}, \mathrm{Ba})_{5}\left(\mathrm{PO}_{4}\right)_{3} \mathrm{Cl}: \mathrm{Eu}^{2+} \\
\mathrm{BaMg}_{2} \mathrm{Al}_{16} \mathrm{O}_{27}: \mathrm{Eu}^{2+}\end{array}$ \\
\hline Green & $\begin{array}{l}\mathrm{CeMgAl}_{11} \mathrm{O}_{19}:\left(\mathrm{Ce}^{3+}\right): \mathrm{Tb}^{3+} \\
\mathrm{LaPO}_{4}: \mathrm{Ce}^{3+}: \mathrm{Tb}^{3+} \\
\mathrm{GdMgB}_{5} \mathrm{O}_{10}: \mathrm{Ce}^{3+}: \mathrm{Tb}^{3+}\end{array}$ \\
\hline Red & $\mathrm{Y}_{2} \mathrm{O}_{3}: \mathrm{Eu}^{3+}$ \\
\hline Blue-Green & $\begin{array}{l}(\mathrm{Ba}, \mathrm{Ca}, \mathrm{Mg})_{5}\left(\mathrm{PO}_{4}\right)_{3} \mathrm{Cl}: \mathrm{Eu}^{2+} \\
2 \mathrm{SrO}-0.84 \mathrm{P}_{2} \mathrm{O}_{5}-0.16 \mathrm{~B}_{2} \mathrm{O}_{3}: \mathrm{Eu}^{2+} \\
\mathrm{Sr}_{4} \mathrm{Al}_{14} \mathrm{O}_{25}: \mathrm{Eu}^{2+}\end{array}$ \\
\hline
\end{tabular}

The metric used to qualify light output from a lamp is the lumen, and this metric constitutes the numerator in the efficacy ratio of lumens per watt. Lumens are a measurement of the radiometric energy emitted from a light source weighted by the response function of the human eye $(\mathrm{V}(\lambda)$ ), which varies for different light wavelengths. For instance, the eye is less sensitive to blue or red light, but is more sensitive to green and yellow-green light (around $550 \mathrm{~nm}$ ). Thus, the efficacy metric used to compare and regulate fluorescent lamps will vary with the different color mixes of the white-light simply due to the sensitivity of the human eye to those colors. And, for those fluorescent lamps that have a high CCT (e.g., > $5000 \mathrm{~K}$ ) the light emission contains more blue light than the lower color temperatures, therefore these lamps will have a lower efficacy measurements because the human eye isn't as sensitive to blue. DOE accounted for this phenomenon in its recent fluorescent lamps standards rulemaking where high CCT lamps were assigned a slightly lower efficacy requirement.

Given the input that has been provided by industry, phosphor technology is similar to that of UV-reflective coatings, in that improved versions are already commercialized and industry continues to make incremental improvements. For this reason, two diamonds are shown in the technology maturity continuum below, reflecting the fact that today's lamps incorporate this technology and that new and improved coatings are still being developed by manufacturers.

\begin{tabular}{|c|c|c|c|c|c|c|}
\hline \multicolumn{7}{|c|}{ Technology Maturity Stage } \\
\hline $\begin{array}{c}\text { Basic Science } \\
\text { Research }\end{array}$ & $\begin{array}{c}\text { Applied } \\
\text { Research }\end{array}$ & $\begin{array}{c}\text { Exploratory } \\
\text { Development }\end{array}$ & $\begin{array}{c}\text { Advanced } \\
\text { Development }\end{array}$ & $\begin{array}{c}\text { Engineering } \\
\text { Development }\end{array}$ & $\begin{array}{c}\text { Product } \\
\text { Demonstration }\end{array}$ & $\begin{array}{c}\text { Commercialization } \\
\text { and Sales }\end{array}$ \\
\hline & & & & & & \\
& & & & & & \\
\hline
\end{tabular}




\subsection{Lamp Fill Gas}

Fluorescent lamps have a mixture of fill gases which impact lamp ignition and operating voltage, mercury molecule ionization and the lamp's operating life through the re-deposition of evaporated electrode coating. Manufacturers will vary the fill gas chemistry (including relative proportions) as well as the pressure of the gas. The molecular weight of gases affects mercury ion mobility and electrons in the plasma. Gases with lower molecular weight will generally have a higher efficacy because the mobility of mercury ions and electrons increases. This increases the electron temperature of the plasma, facilitating recombination and ultimately raising the UV radiation to saturation level. However, the mobility of ions and electrons should not exceed the optimal point, beyond which they may reach the lamp glass surface itself, preventing emission and reducing UV output.

Standard fluorescent lamps generally are filled with argon gas. Energy-saver lamps incorporate argon blended with krypton, neon and/or xenon. The optimal mix is a function of the lamp length and diameter, the phosphors and the pressure. The figure below illustrates how the UV output varies by watts of power per foot of electrical arc in the tube for the common fill gases. At higher power densities, such as might be found in a high-output fluorescent lamp, neon allows for higher UV radiation, and therefore higher lamp efficacy.

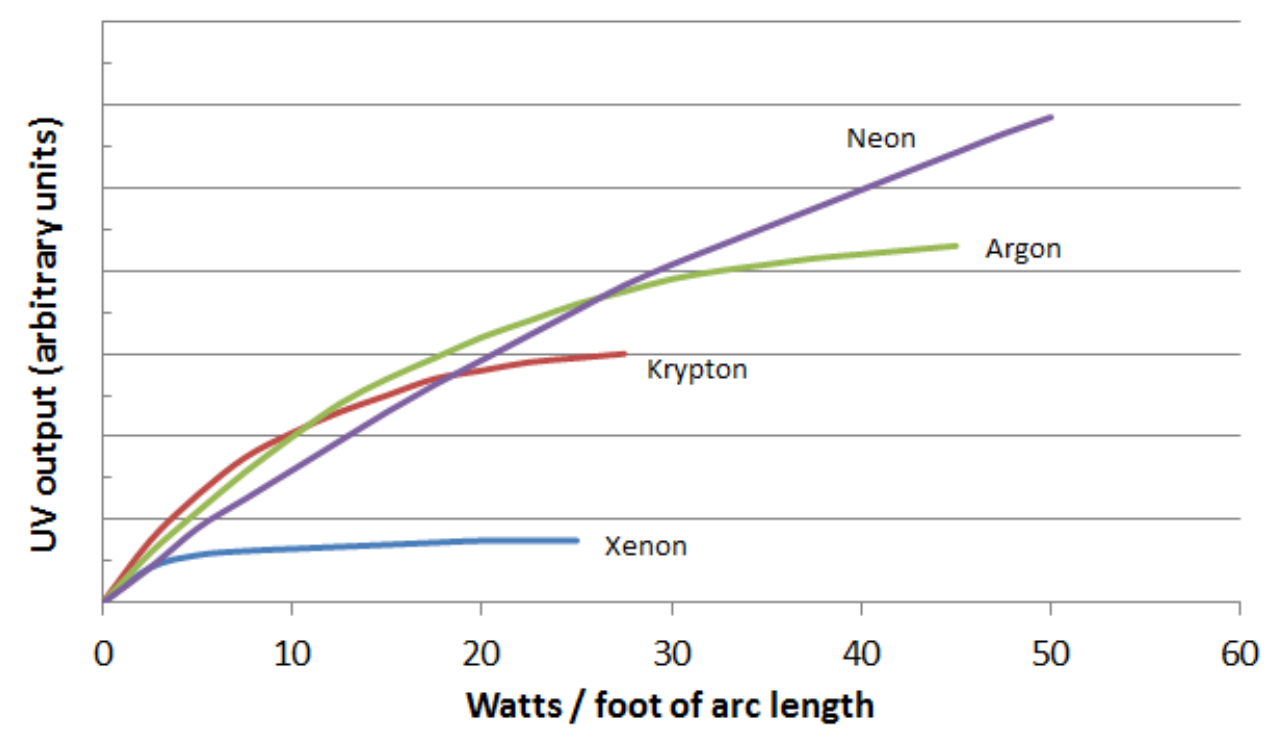

Figure 3-1. Lamp Fill Gas UV Output by Power Density

The internal gas pressure of these lamps is usually low, ranging from 100 to 400 Pascals (approximately $0.3 \%$ of standard atmospheric pressure, $100 \mathrm{kPa}$ ). Lower pressures are generally associated with high efficacy because as the pressure exceeds a certain point, elastic scattering increases which decreases the mobility of ions and electrons. That reduction in mobility results in a lower total UV radiation from the lamp, decreasing efficacy. However, lower pressure also shortens the lamp lifetime by accelerating the evaporation of the electrode coating. During lamp operation, the emissive coating on the electrodes slowly evaporates, and some of these molecules subsequently collide with the lamp fill gas and are re-deposited back on the filament. These 
collisions can be increased through larger atom mass of the gas fill or by increasing the pressure in the lamp. This re-deposition of the evaporated electrode coating results in an increased lamp lifetime. Therefore, the lamp fill gas chemistry and pressure must be optimized to obtain a balance between lamp lifetime and enhanced mobility of the ions and electrons.

The industry researchers interviewed indicated that lamp fill-gas continues to be an area of active research and development. As new, more efficacious lamps are introduced, the fill gas mixture and pressure will be modified and adjusted to account for changes in the lamp that optimize performance and reduce power consumption. Fill gas is both commercialized and is continuing to be an area of advanced development and engineering development, thus the diamond is shown on the cusp of those stages.

\begin{tabular}{|c|c|c|c|c|c|c|}
\hline \multicolumn{7}{|c|}{ Technology Maturity Stage } \\
\hline $\begin{array}{c}\text { Basic Science } \\
\text { Research }\end{array}$ & $\begin{array}{c}\text { Applied } \\
\text { Research }\end{array}$ & $\begin{array}{c}\text { Exploratory } \\
\text { Development }\end{array}$ & $\begin{array}{c}\text { Advanced } \\
\text { Development }\end{array}$ & $\begin{array}{c}\text { Engineering } \\
\text { Development }\end{array}$ & $\begin{array}{c}\text { Product } \\
\text { Demonstration }\end{array}$ & $\begin{array}{c}\text { Commercialization } \\
\text { and Sales }\end{array}$ \\
\hline & & & & & & \\
\hline
\end{tabular}

\subsection{Improved Electrode Coatings}

The electrodes in fluorescent lamps are usually tungsten filaments coated with a material to increase their electron emissivity. The coating on the filaments enables electrons to pass into the fill gas via thermionic emission at the operating voltages of the lamp. The electrodes have to emit a sufficient number of electrons in order to ionize the gas and thereby maintain the UV arc and lamp discharge. Electrode coating improvements will improve the emissivity of electrons and reduce the lamp power necessary to maintain the arc, which in turn will increase overall lamp efficacy. The typical coatings include barium oxide $(\mathrm{BaO})$, calcium oxide $(\mathrm{CaO})$, and strontium oxide ( $\mathrm{SrO}$ ). Other materials that have also been added to these coatings to create a coating 'mix' include zirconium oxide ( $\mathrm{ZrO})$ and silicon carbide (SiC). These materials have been investigated for their ability to improve electron emission.

The electrode coatings have a critical and direct relationship to the lifetime of the lamp. During normal use of the lamp, the electrode coating is slowly sputtered away by bombardment with electrons and mercury ions. In addition, a small amount is sputtered off each time the tube is started - hence, the method of starting the lamp has will have a significant impact on overall lamp lifetime. Typically, lamps are designed to operate for approximately 3 hours per on-cycle, and will normally run out of electrode coating before other parts of the lamp fail. The remains of the sputtered coatings are visible as dark marks at the ends of the fluorescent tube. When the emissive coating has been depleted, the cathode cannot pass sufficient electrons into the fill gas to maintain the discharge at the designed voltage, and the lamp stops working.

Research into improved electrode coatings is on-going, both in terms of improving electron emissivity and extending the operating life of lamps. The technology maturity continuum reflects this aspect of the technology, indicating that improved electrode coatings are 
commercialized and that new ones are in development - both at the advanced stage and the engineering (i.e., manufacturing/production line) stage.

\begin{tabular}{|c|c|c|c|c|c|c|}
\hline \multicolumn{7}{|c|}{ Technology Maturity Stage } \\
\hline $\begin{array}{c}\text { Basic Science } \\
\text { Research }\end{array}$ & $\begin{array}{c}\text { Applied } \\
\text { Research }\end{array}$ & $\begin{array}{c}\text { Exploratory } \\
\text { Development }\end{array}$ & $\begin{array}{c}\text { Advanced } \\
\text { Development }\end{array}$ & $\begin{array}{c}\text { Engineering } \\
\text { Development }\end{array}$ & $\begin{array}{c}\text { Product } \\
\text { Demonstration }\end{array}$ & $\begin{array}{c}\text { Commercialization } \\
\text { and Sales }\end{array}$ \\
\hline & & & & & & \\
\hline
\end{tabular}

\subsection{Multi-Photon Phosphors}

Research has been conducted into multi-photon phosphors, also called "quantum-cutters", which emit two visible light photons in response to excitation from one UV light photon. For example, researchers at Georgia Tech developed an oxide-based phosphor doped with praseodymium and the atoms of at least one activator and filed a patent for this material. In interviews with the industry researchers however, this technology was not considered likely to be commercialized. Indeed, one researcher said that while the concept was promising, there were too many technical drawbacks that would need to be resolved including the light color output, color stability, phosphor lifetime and so on.

Given the input from industry researchers, and the fact that this technology still has many technical draw-backs that would need to be overcome before the technology would be advanced enough to start looking at production, multi-photon phosphors is classified as exploratory development.

\begin{tabular}{|c|c|c|c|c|c|c|}
\hline \multicolumn{7}{|c|}{ Technology Maturity Stage } \\
\hline $\begin{array}{c}\text { Basic Science } \\
\text { Research }\end{array}$ & $\begin{array}{c}\text { Applied } \\
\text { Research }\end{array}$ & $\begin{array}{c}\text { Exploratory } \\
\text { Development }\end{array}$ & $\begin{array}{c}\text { Advanced } \\
\text { Development }\end{array}$ & $\begin{array}{c}\text { Engineering } \\
\text { Development }\end{array}$ & $\begin{array}{c}\text { Product } \\
\text { Demonstration }\end{array}$ & $\begin{array}{c}\text { Commercialization } \\
\text { and Sales }\end{array}$ \\
\hline & & & & & & \\
& & & & & \\
\hline
\end{tabular}

\subsection{Quantum Dots}

Quantum dots are nanometer-size pieces of semiconductor material, such as cadmium selenide, which fluoresce when they are excited by photons or electrons. Generally, a quantum dot that is two nanometers in diameter emits blue light, a four nanometer dot emits green, and a six nanometer dot emits red. By creating a mix of different quantum dots, a quantum dot layer can be created (similar to a phosphor layer in today's fluorescent lamps) that will precisely and consistently emit the desired light wavelength. 
Much of the research effort in quantum dots today is focused on LED applications, where researchers are developing quantum dot thin films that will fit over a blue or UV-light LED and down-convert the LED output into visible light. Quantum dots promise to be more efficient than phosphors, and to have more consistent color. A company called QD Vision has produced an optical coating that quantum dots that converts a blue LED to a high-quality white light with a CRI of 90 and high efficacy - 65 lumens per watt. QD vision started manufacturing and selling these lamps in $2010 .^{6}$

Ultimately, the concept would be to have a layer of quantum dots that can substitute for the phosphor layer on a fluorescent lamp and thereby convert the UV light into a consistent, highquality white-light. However, it is unclear whether this technology will be commercialized, as there are technical issues to overcome in addition to the cost of the quantum dot material itself.

Quantum dots have demonstrated their capability to convert UV radiation into quality white-light using UV LEDs. However, we are not aware of anyone constructing and demonstrating quantum dots as replacements for phosphors in fluorescent lamps, therefore, this technology has been classified as at the engineering development for fluorescent lamps. This is due to the fact that the technology will likely require some further engineering development before a prototype lamp could be built and demonstrated.

\begin{tabular}{|c|c|c|c|c|c|c|}
\hline \multicolumn{7}{|c|}{ Technology Maturity Stage } \\
\hline $\begin{array}{c}\text { Basic Science } \\
\text { Research }\end{array}$ & $\begin{array}{c}\text { Applied } \\
\text { Research }\end{array}$ & $\begin{array}{c}\text { Exploratory } \\
\text { Development }\end{array}$ & $\begin{array}{c}\text { Advanced } \\
\text { Development }\end{array}$ & $\begin{array}{c}\text { Engineering } \\
\text { Development }\end{array}$ & $\begin{array}{c}\text { Product } \\
\text { Demonstration }\end{array}$ & $\begin{array}{c}\text { Commercialization } \\
\text { and Sales }\end{array}$ \\
\hline & & & & & & \\
& & & & & & \\
\hline
\end{tabular}

${ }^{6}$ For more information about QD Vision's lamp, visit: http://www.qdvision.com/quantum-lightoptic However, this lamp is a replacement for an incandescent reflector lamp, not a fluorescent tube. 


\section{Screening Analysis Preview}

The purpose of the screening analysis is to review the design options discussed in Chapter 3 which improve the efficiency of fluorescent lamps and determine which of these options would be able to be evaluated in an energy conservation standards rulemaking. The screening analysis in the context of this report is a preliminary assessment based on the information available from the research and interviews. The findings of this review are indicative only, and should not be taken as a comprehensive screening analysis, such as DOE conducts in a regulatory rulemaking.

\subsection{Introduction}

The screening analysis is conducted by applying a set of screening criteria to the design options identified as means of making a fluorescent lamp more efficient. The criteria that shall be applied when conducting a screening analysis are contained in the US Code of the Federal Register, (10 CFR Part 430, Subpart C, Appendix A at 4(a)(4) and 5(b)):

(1) Technological feasibility. Technologies incorporated in commercial products or in working prototypes will be considered technologically feasible;

(2) Practicability to manufacture, install and service. If mass production of a technology in commercial products and reliable installation and servicing of the technology could be achieved on the scale necessary to serve the relevant market at the time of the effective date of the standard, then that technology will be considered practicable to manufacture, install, and service.

(3) Adverse impacts on product utility or product availability. If a technology is determined to have significant adverse impact on the utility of the product to significant subgroups or consumers, or result in the unavailability of any covered product type with performance characteristics (including reliability), features, sizes, capacities, and volumes that are substantially the same as products generally available in the U.S. at the time, it will not be considered further.

(4) Adverse impacts on health or safety. If it is determined that a technology will have significant adverse impacts on health or safety, it will not be considered further.

This section considers each of the energy-efficiency measures identified in Chapter 3 of this report, and describes how the criteria may or may not apply to each of the technology options.

\subsection{Screening of Efficiency Measures}

There are seven technology options discussed in this report which contemplate improving the efficacy of fluorescent lamps. These include varying lamp diameter, improved UV-reflective coatings, phosphors, lamp fill gas, improved electrode coatings, multi-photon phosphors and quantum dots. The following table presents these seven options, and then has a column for each of the options that is indicative of whether this technology is likely to comply with the 
requirements of a screening analysis. Following the table, a discussion ensues on the technology options which appear to have issues pertaining to the screening analysis criteria.

Table 4-1. Initial Screening Analysis of Technology Options Discussed

\begin{tabular}{|c|c|c|c|c|}
\hline $\begin{array}{l}\text { Technology } \\
\text { Option }\end{array}$ & $\begin{array}{l}\text { Technical } \\
\text { Feasibility }\end{array}$ & $\begin{array}{c}\text { Practicability to } \\
\text { Manuf., Install } \\
\text { and Service }\end{array}$ & $\begin{array}{c}\text { Adverse Impacts } \\
\text { on Utility or } \\
\text { Availability }\end{array}$ & $\begin{array}{c}\text { Adverse Impacts } \\
\text { on Health or } \\
\text { Safety }\end{array}$ \\
\hline $\begin{array}{l}\text { Varying Lamp } \\
\text { Diameter }\end{array}$ & No issue & Potential issue & No issue & No issue \\
\hline $\begin{array}{l}\text { UV-Reflective } \\
\text { Coatings }\end{array}$ & No issue & No issue & No issue & No issue \\
\hline Phosphors & No issue & No issue & No issue & No issue \\
\hline Lamp Fill Gas & No issue & No issue & No issue & Potential issue \\
\hline $\begin{array}{l}\text { Improved } \\
\text { Electrode } \\
\text { Coatings }\end{array}$ & No issue & No issue & No issue & No issue \\
\hline $\begin{array}{l}\text { Multi-Photon } \\
\text { Phosphors }\end{array}$ & Potential issue & Potential issue & Uncertain & Uncertain \\
\hline Quantum Dots & Potential issue & Potential issue & Uncertain & Uncertain \\
\hline
\end{tabular}

Of the seven technology options, the UV-reflective coatings, phosphors and improved electrode coatings do not appear to have any issues that would warrant screening them out of an engineering analysis. These are all technologies used in the market today and the research being done is focused on incremental improvements to these commercially available technologies.

The variance of lamp diameter has a potential issue concerning the practicability to manufacture, install and service. It is possible that if lamp diameters change and the new lamps are not able to be retrofitted into existing fluorescent luminaires that it would create a problem for reliable installation of the lamps as well as changing the optical design and performance of the luminaire, necessitating its replacement. This is an issue that would need to be evaluated if new lamp diameters were introduced into the market.

The technology option of lamp fill gas may also need to be evaluated from the standpoint of health and safety, particularly if the lamp fill gas pressure is increased or decreased. If this change in pressure makes a lamp operating on certain types of ballasts have increased catastrophic failure mechanisms (i.e., shattered glass tubes), then those technology options may need to be screened out. 
Finally, multi-photon phosphors and quantum dots have not been demonstrated in prototype form, thus there may be issues pertaining to both the technical feasibility and the practicability to manufacture. These issues would require further study, should a commercially available option be proposed or brought to market. Furthermore, given the lack of any prototype, it is impossible to make an assessment of whether these two technology options would also not have any adverse impacts on product utility or product availability, nor any adverse impacts on health or safety. In the event that these technology options were proposed, then this assessment would need to be done. 


\section{Manufacturers and Markets}

Fluorescent lighting is a technology that has been commercially available for nearly 80 years.

Over that time period, the technology has improved from around 40 lumens per watt to over 110 lumens per watt. Industry has agreed certain norms and standards which have determined a consistent set of sockets, lamp diameters, operating currents and other design features that provide for multiple suppliers of fluorescent lamps.

\subsection{Manufacturers of Fluorescent Lamps}

The fluorescent lamp market is dominated by three large global corporations who are also industry leaders in other lighting technologies, such as incandescent and high intensity discharge. While there are other smaller companies that have niche fluorescent products and/or who compete with these three large companies, more than $80 \%$ of the fluorescent lamps sold in the United States are produced (or branded) by these companies:

- General Electric Consumer and Industrial North America

- OSRAM Sylvania

- Philips Lighting North America

\subsection{Market Size and Shipments}

The following table provides shipment estimates for selected fluorescent lamps that were published by DOE in the fluorescent lamp rulemaking completed in June 2009. The table below provides shipments of the National Electrical Manufacturer Association (NEMA) members, which are assumed to represent the totality of shipments of these fluorescent lamps into the US market (including the three companies mentioned above). Any other manufacturers or privatelabeled fluorescent lamps sold would constitute less than $5 \%$ of the shipments presented. It should be noted that NEMA also provided shipment data for 2006 and 2007 to DOE, however that data was kept confidential at the request of NEMA, and thus it has not been included in this table or the analysis prepared for this report.

As shown in the table, the total annual shipments between 2001 and 2005 were approximately 450 million units. 
Table 5-1. US Shipments Provided by NEMA for Eight Common Fluorescent Lamp Types

\begin{tabular}{|l|r|r|r|r|r|}
\hline \multicolumn{1}{|c|}{ Lamp Type } & \multicolumn{1}{c|}{$\mathbf{2 0 0 1}$} & $\mathbf{2 0 0 2}$ & \multicolumn{1}{c|}{$\mathbf{2 0 0 3}$} & \multicolumn{1}{c|}{$\mathbf{2 0 0 4}$} & \multicolumn{1}{c|}{$\mathbf{2 0 0 5}$} \\
\hline T12 Four-Foot Medium Bipin & 212,564 & 205,998 & 181,931 & 175,850 & 162,664 \\
\hline T8 Four-Foot Medium Bipin & 164,129 & 163,632 & 172,294 & 195,698 & 215,530 \\
\hline T12 Eight-Foot Single Pin Slimline & 43,265 & 41,443 & 37,170 & 36,263 & 33,636 \\
\hline T8 Eight-Foot Single Pin Slimline & 4,405 & 5,300 & 5,183 & 5,727 & 5,176 \\
\hline T12 Two-Foot U-Shaped & 9,672 & 9,314 & 9,460 & 7,014 & 8,839 \\
\hline T8 Two-Foot U-Shaped & 8,014 & 6,784 & 7,018 & 9,224 & 8,659 \\
\hline T12 Eight-Foot Recessed Double Contact HO & 23,887 & 24,398 & 24,206 & 24,591 & 25,442 \\
\hline T8 Eight-Foot Recessed Double Contact HO & 691 & 647 & 467 & 674 & 420 \\
\hline Total Lamps (thousands of units) & 466,627 & 457,516 & 437,729 & 455,041 & 460,366 \\
\hline
\end{tabular}

Due to the fact that this report is not using the shipment data from 2006 and 2007 that was provided to DOE under a confidentiality agreement with NEMA, the shipment projections provided below to assess how these eight lamp types are changing over time may not align with those published by DOE in 2009 rulemaking. A least squares fit linear regression was applied to each of the eight lamps, and the shipments were projected forward from 2006 through 2010. The results appear in the table below. The overall general trend is showing a slight decline, with approximately 445 million units shipped in 2010.

Table 5-2. US Shipments Estimate Projection Based on NEMA's 2001-2005 Data

\begin{tabular}{|l|r|r|r|r|r|}
\hline \multicolumn{1}{|c|}{ Lamp Type } & \multicolumn{1}{c|}{$\mathbf{2 0 0 6}$} & \multicolumn{1}{c|}{$\mathbf{2 0 0 7}$} & \multicolumn{1}{c|}{$\mathbf{2 0 0 8}$} & \multicolumn{1}{c|}{$\mathbf{2 0 0 9}$} & \multicolumn{1}{c|}{$\mathbf{2 0 1 0}$} \\
\hline T12 Four-Foot Medium Bipin & 148,817 & 135,822 & 122,827 & 109,833 & 96,838 \\
\hline T8 Four-Foot Medium Bipin & 222,717 & 236,204 & 249,691 & 263,177 & 276,664 \\
\hline T12 Eight-Foot Single Pin Slimline & 31,024 & 28,580 & 26,136 & 23,693 & 21,249 \\
\hline T8 Eight-Foot Single Pin Slimline & 5,749 & 5,946 & 6,143 & 6,340 & 6,537 \\
\hline T12 Two-Foot U-Shaped & 7,670 & 7,273 & 6,877 & 6,480 & 6,084 \\
\hline T8 Two-Foot U-Shaped & 9,059 & 9,432 & 9,805 & 10,178 & 10,551 \\
\hline T12 Eight-Foot Recessed Double Contact HO & 25,496 & 25,826 & 26,156 & 26,487 & 26,817 \\
\hline T8 Eight-Foot Recessed Double Contact HO & 425 & 374 & 322 & 271 & 219 \\
\hline Total Lamps (thousands of units) & 450,957 & 449,457 & 447,957 & 446,458 & 444,958 \\
\hline
\end{tabular}

These projections were then analyzed to study the trends that are observable for the different lamp types. In the table below, the year 2005 was set as the reference year (i.e., shipment index 
set to equal 1.0), and the proportion of shipments for each lamp type relative to 2005 was calculated. This shows a trend that over the last five years, shipments of T12 lamps are generally decline (with the exception of eight-foot high-output T12 lamps) and most of the T8 lamp types are increasing market share. The eight foot recessed double contact high-output lamps are exhibiting a slight growth in T12 and a sharp decline in T8. Part of the reason for this trend is that the eight foot recessed double contact lamps are primarily used in industrial applications and they already operate on (high frequency) electronic ballasts, so the value proposition and benefit of migrating to T8 lamps is not as strong as it is for other lamps. In addition, these lamp types will be competing for market share with high-bay and low-bay high-intensity discharge lamps including metal halide and ceramic metal halide, which are improving in both light color and quality.

Table 5-3. Shipment Trends for the Eight Fluorescent Lamps (2005 = Index of 1)

\begin{tabular}{|c|c|c|c|c|c|c|}
\hline Lamp Type & 2005 & 2006 & 2007 & 2008 & 2009 & 2010 \\
\hline T12 Four-Foot Medium Bipin & 1.0 & 0.9 & 0.8 & 0.8 & 0.7 & 0.6 \\
\hline T8 Four-Foot Medium Bipin & 1.0 & 1.0 & 1.1 & 1.2 & 1.2 & 1.3 \\
\hline T12 Eight-Foot Single Pin Slimline & 1.0 & 0.9 & 0.8 & 0.8 & 0.7 & 0.6 \\
\hline T8 Eight-Foot Single Pin Slimline & 1.0 & 1.1 & 1.1 & 1.2 & 1.2 & 1.3 \\
\hline T12 Two-Foot U-Shaped & 1.0 & 0.9 & 0.8 & 0.8 & 0.7 & 0.7 \\
\hline T8 Two-Foot U-Shaped & 1.0 & 1.0 & 1.1 & 1.1 & 1.2 & 1.2 \\
\hline T12 Eight-Foot Recessed Double Contact HO & 1.0 & 1.0 & 1.0 & 1.0 & 1.0 & 1.1 \\
\hline T8 Eight-Foot Recessed Double Contact $\mathrm{HO}$ & 1.0 & 1.0 & 0.9 & 0.8 & 0.6 & 0.5 \\
\hline
\end{tabular}

\subsection{Estimate of the Installed Stock}

Taking the shipment data discussed in section 5.2, an estimate of the installed stock of covered fluorescent lamps can be prepared. The flow-diagram to the right describes the five step process followed to arrive at the estimate prepared for this study. In essence, the inventory stock model takes into account shipments of lamps over a number of years, the catalogue lifetimes for those lamps, the typical operating hours, and an S-curve failure function that is representative of fluorescent lamps. The stock are then tracked year on year and summed together to create the total national inventory.

Shipments of covered fluorescent lamps in the US from NEMA

Derive catalogue lifetime (50\% failure) from manufacturer catalogues

Estimate operating hours, taking into account commercial applications

Apply a known failure function for lighting products (S-curve)

Sum annual shipments over sufficient time to capture legacy years 
Concerning the failure function, the published lamp manufacturer catalogue lifetimes represent an average rating, indicative of when $50 \%$ of the lamps have failed. This means there will be some lamps that fail before the rated lifetime and some that fail afterwards. The shape of the lifetime failure curve represents an "S-curve" which rises slowly initially (indicating few lamp failures in the first half of the life), then rises rapidly through the $50 \%$ point (which is the published average lifetime) before it gradually slows down approaching $100 \%$ of failures. This curve means that very few lamps (a low percentage) will fail before the rated catalogue lifetime and similarly, a small percentage of lamps will extend beyond the rated life.

This S-Curve lamp failure function is defined by the equation

$$
y(t)=1 /\left(1+b^{-b(t-a)}\right)
$$

where:

$\mathrm{y}(\mathrm{t})$ is the fraction of the market remaining

"a” represents the time to $50 \%$ of failure

"b" represents the steepness of the slope

The "a” term used is defined as the catalogue life divided by the weighted operating hours and varies according to the lamp type and installation. For this study, an average of 10 hours per day, 365 days per year was used as the operating hours for all installations and 20,000 hours operating life for the lamps. The "b" term is set at 2.0 to be indicative of typical lamp-life failure curves, having a small number of failures in the beginning, rising steeply through the $50 \%$ mark and then slowing down as it approaches 100\% failures.

The table below presents the findings of this inventory stock model for the eight types of covered fluorescent lamps. The trends in stock follow the same trends observed in Table 5-3 above, which tend to show increasing stock of T8 lamps and declining shipments of T12 lamps.

Table 5-4. Estimated Installed Stock of Fluorescent Lamps in the US Market (000 units)

\begin{tabular}{|l|r|r|r|r|r|r|}
\hline & \multicolumn{1}{c|}{$\mathbf{2 0 1 0}$} & \multicolumn{1}{c|}{$\mathbf{2 0 1 1}$} & \multicolumn{1}{c|}{$\mathbf{2 0 1 2}$} & \multicolumn{1}{c|}{$\mathbf{2 0 1 3}$} & \multicolumn{1}{c|}{$\mathbf{2 0 1 4}$} & \multicolumn{1}{c|}{$\mathbf{2 0 1 5}$} \\
\hline T12 4ft MBP & 779,591 & 701,598 & 623,750 & 546,052 & 468,391 & 390,736 \\
\hline T8 4ft MBP & $1,449,128$ & $1,527,604$ & $1,606,908$ & $1,687,203$ & $1,767,744$ & $1,848,329$ \\
\hline T12 8ft Slim & 204,127 & 186,918 & 169,544 & 152,214 & 134,922 & 117,641 \\
\hline T8 8ft Slim & 41,830 & 43,122 & 44,577 & 46,039 & 47,449 & 48,845 \\
\hline T12 2ft U & 42,641 & 40,233 & 37,760 & 35,364 & 32,989 & 30,618 \\
\hline T8 2ft U & 57,473 & 59,564 & 61,763 & 63,986 & 66,215 & 68,443 \\
\hline T12 8ft RDC & 182,350 & 184,790 & 187,084 & 189,369 & 191,691 & 194,024 \\
\hline T8 8ft RDC & 2,703 & 2,317 & 1,947 & 1,589 & 1,227 & 863 \\
\hline
\end{tabular}




\section{References}

Chapter 3. Market and Technology Assessment, Energy Conservation Standards and Test Procedures for General Service Fluorescent Lamps and Incandescent Reflector Lamps; Final Rule. US Department of Energy. July 14, 2009.

Desroches, Louis-Benoit, and Karina Garbesi, 2011. Max Tech and Beyond: Maximizing Appliance and Equipment Efficiency by Design. Lawrence Berkeley National Laboratory, LBNL-4998E.

General Electric Lamp and Ballast Catalogue, GE Consumer and Industrial North America, November 2011.

New class of phosphors for 'de luxe' fluorescent lamps, by J.M.P.J. Verstegen, Lighting Division, NV Philips, Eindhoven, Netherlands. Published in Lighting Research and Technology, vol. 6, no.1, 31-32 (1974).

Oxide-based quantum cutter method and phosphor system, patent application submitted by Park, Woun-jhang (Boulder, CO, US); Summers, Christopher J. (Dunwoody, GA, US); Do, Young-rag (Seoul, KR); Park, Do-hyung (Suwon-city, KR); and Yang, Hong-geun (Suwon-City, KR). Application 09/987697, published May 15, 2003. Assignee: Georgia Tech Research Corporation (Atlanta, GA, US).

Personal Communication with industry technical experts at Philips Lighting; Havells-Sylvania and OSRAM/Sylvania, June 2010.

Phosphor Handbook, Second Edition. Edited by William M. Yen, Shigeo Shionoya, Hajime Yamamoto. CRC Press, Taylor \& Francis Group, LLC, Boca Raton, Florida. 2007.

Rea, Mark S., ed. The IESNA Lighting Handbook: Reference \& Application, 9th Edition. 2000. The Illuminating Engineering Society of America: New York, New York

Strategic Technology Management, Frederick Betz, McGraw-Hill Engineering and Technology Management Series, McGraw-Hill, Inc., New York, 1993.

U.S. Lighting Market Characterization Volume II: Energy Efficient Lighting Technology Options; Prepared by Navigant Consulting for the US Department of Energy. September 2005. 